\title{
Diagnosis and Management of Prostate Cancer in Urology
}

\section{Cyril Kamadjou1, Kimassoum Rimtebaye², Divine Eyongeta ${ }^{3}$, Annie Kameni' ${ }^{1}$, Justin Kamga4, Bertin Njinou1}

\author{
${ }^{1}$ Medico-Surgical Center of Urology and Mini Invasive Surgery, Douala, Cameroon \\ ${ }^{2}$ National General Referal Hospital, N'Djamena, Chad \\ ${ }^{3}$ Regional Hospital, Limbe, Cameroon \\ ${ }^{4}$ General Hospital, Yaounde, Cameroon \\ Email: melinarim@yahoo.fr
}

How to cite this paper: Kamadjou, C., Rimtebaye, K., Eyongeta, D., Kameni, A., Kamga, J. and Njinou, B. (2018) Diagnosis and Management of Prostate Cancer in Urology. Open Journal of Urology, 8, 161-165.

https://doi.org/10.4236/oju.2018.85016

Received: February 26, 2018

Accepted: May 8, 2018

Published: May 11, 2018

Copyright (C) 2018 by authors and Scientific Research Publishing Inc. This work is licensed under the Creative Commons Attribution International License (CC BY 4.0).

http://creativecommons.org/licenses/by/4.0/

Open Access

\begin{abstract}
Introduction: Describe the diagnostic approach and management of prostate cancer at the medico-surgical center of urology in Douala, Cameroon. Materials and methods: This was a descriptive retrospective study reviewing 100 patient's records suffering of prostate cancer from January 2011 to December 2015. The studied variables were clinical, paraclinical and therapeutic. Results: The mean age was 65 years with extrems of 50 and 85 . Rectal examination was suggestive in 63 cases. 7 patients had a family history. The average PSA rate was $43.23 \mathrm{ng} / \mathrm{ml}$. Histology has concluded to an adenocarcinoma in all patients. The gleason score was equal or greater than to 7 for 53 patients (53\%). The extended assessment revealed distant metastasis for 43 patients. The treatment was: surveillance $(\mathrm{n}=33)$, total laparoscopic radical prostatectomy $(n=24)$, surgical hormone therapy $(n=10)$, medical hormone therapy $(\mathrm{n}=28)$ and chemotherapy coupled with hormone therapy $(\mathrm{n}=5)$. Conclusion: Prostate cancer is common in Douala; its diagnosis is made late. Radical treatment is possible for localized cancers, hence the interest of early detection.
\end{abstract}

\section{Keywords}

Prostate Cancer, Adenocarcinoma, Prostatectomy, Hormone Therapy

\section{Introduction}

Prostate cancer is the first urological cancer of men and the second leading cause of death caused by cancer [1] [2]. The advent of PSA and the development of medical imaging allow early diagnosis at a localized stage making possible cura- 
tive treatment. In developing countries where patients consult at a late symptomatic stage [3], curative treatment usually gives way to palliative treatment. Emphasis should be placed on awareness and early detection so that all men over the age of 40 can consult an urologist at least once a year. The purpose of our study is to introduce our diagnostic and therapeutic approach to prostate cancer at the Medico-surgical Center of Urology (CMCU) in Douala, Cameroon.

\section{Materials and Methods}

This was a descriptive retrospective study reviewing 100 patient's records suffering of prostate cancer from January 2011 to December 2015for the first in CMCU. Patients came spontaneously or were referred by colleagues. Were included patients whose diagnosis of prostate cancer was selected on the basis of a panel of clinical and paraclinical arguments, and had received care at the CMCU. Were excluded those who left the follow-up and those who refused treatment when informed of the risk of erectile dysfunction or urinary incontinence after treatment. Patients with non-prostatic urologic cancers were not included. These patients had a clinical and paraclinical assessment. Clinical variables included: age, medical and family history, general condition, urinary disorders of the lower urinary tract and digital rectal examination. Paraclinical variables included total PSA, the rate of urea and blood creatinine, renal, vesical and prostatic ultrasound, transrectal prostate ultrasound-guided in sextant, histological analysis of prostate biopsy cores, the thoraco-abdominal and pelvic CT scans, magnetic resonance imaging and bone scintigraphy. The therapeutic variables included: therapeutic abstention, radical laparoscopic prostatectomy, surgical hormone therapy, medical hormone therapy and chemotherapy. The reasons for the study were explained to the patients and their consent was obtained for the anonymous use for scientific purposes of the pictures.

\section{Results}

In three years of activities, we diagnosed 100 patients with prostate cancer, all stage toghether. The average age of the patients was 65 years with extremes of 50 and 85 years. The notion of family history (first degree of kinship) is found in 7 patients. Digital rectal examination had made possible to suspect the diagnosis of prostate cancer in 63 patients. The reasons for consultation were dominated by urinary troubles of the lower urinary tract (64\%). The average PSA was 43.23 $\mathrm{ng} / \mathrm{ml}$ with extremes of 5 and $217 \mathrm{ng} / \mathrm{ml}$. The histological analysis of the prostate cores biopsy led to the diagnosis of certainty of prostate cancer in 93 cases and 7 in other cases by histological analysis of the endoscopic resection chips. Adenocarcinoma (Figure 1) was the only histological type found. The Gleason score was greater than 7 in 53 cases. The extented assessment permitted to objectify for 43 patients with distant metastasis (Figure 2). 30 cases of bone metastasis and 13 lymph nodes mestastasis. The management was surveillance $(n=33)$, total radical laparoscopic prostatectomy $(n=24)$, surgical hormonal therapy 


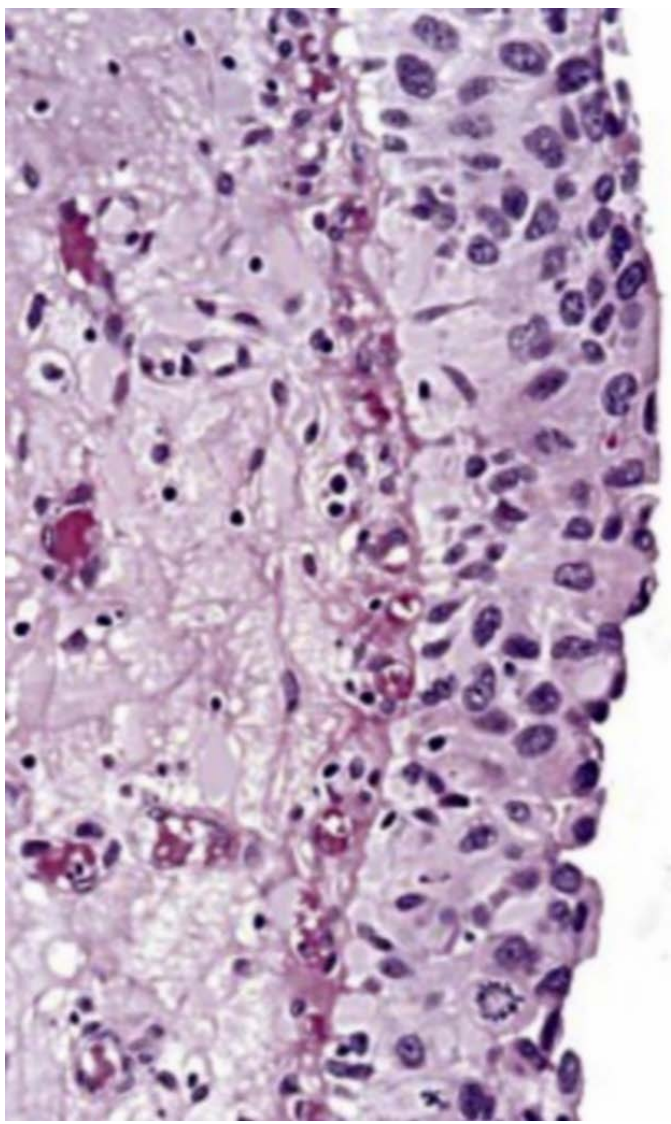

Figure 1. Adenocarcinoma.

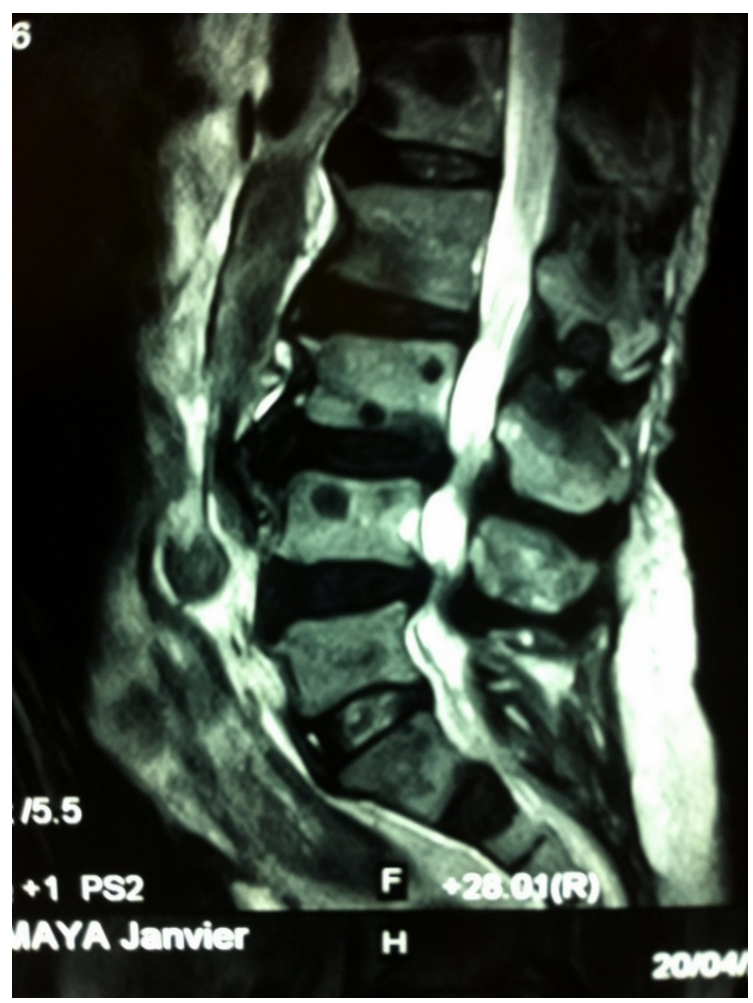

Figure 2. Bonemetastasis. 
$(\mathrm{n}=10)$, medical hormone therapy $(\mathrm{n}=28)$ and hormone therapy followed by chemotherapy $(n=5)$. During the study we registered 2 deaths from patients who received chemotherapy.

\section{Discussion}

Prostate cancer is the first urological cancer of men and the second leading cause of death after lung cancer [4]. Since Huggin's work, focusing on the hormone-dependent nature of prostate cancer and the popularization of the use of PSA, the incidence of prostate cancer is increasing in developed countries [5]. In Africa, epidemiological data are scarce in relation to the absence of a cancer registry as highlighted by the work of Ndoye and al [6]. In Nigeria, a hospital incidence of $127 / 100,000$ for 20,000 deaths is reported [7]. This high incidence reported by the Nigerian study reinforces the thesis that prostate cancer is more common in black African subjects [8] [9] [10]. The mean age of patients is 64.85 years is similar to those found by other African authors [11] [12] [13] confirming that prostate cancer is a cancer of the elderly age.

The study found that patients with a family history of prostate cancer are young because they are all under 55 years of age. Familial prostate cancers are known to be more aggressive and occur at early ages. In this at-risk population, early detection from the age of 40 seems a good strategy for early management as recommended by the American Cancer Association [4] [14]. Evidence-based on rectal examination in sixty-three percent of patients, voiding disorders, bone pain, elevated PSA average, and high Gleason score support the delay in consultation and thus explain the locally advanced or metastatic prostate cancer in our exercise setting. This finding is also reported by many African writers [3] [6]. The high level of PSA corroborates well the development of the metastasis objectified by the extented assessment. The predominance of individualized bone metastasis in bone scintigraphy reinforces the thesis of the osteophilic character of prostate cancer and thus explains bone pain symptomatology reported by patients.

Radical laparoscopic prostatectomy is performed only in a small proportion because of the locally advanced or metastatic prostate cancer requiring thus to practice hormone therapy sometimes associated with chemotherapy in case of resistance to castration. Surgical hormone therapy, synonymous with castration, is very poorly experienced in our context for fear of loss of sexuality and explains the mistrust of some patients to benefit adequate management. Indeed the bilateral orchidectomy, due to the physical absence of the testicles is responsible for a psychological impact dreaded by the patients.

\section{Conclusion}

Prostate cancer is common in Douala where patients usually consult at a late stage or metastatic stage. Radical treatment by laparoscopic prostatectomy is available for localized cancers. Improving management requires screening and 
early consultation.

\section{References}

[1] Villers, A. (2008) Epidémiologie du cancer de la prostate : Article de revue Elsevier. 32, 2-4.

[2] Siegel, R.L., Miller, K.D. and Jemal, A. (2015) Cancer Statistics, 2015. CA: A Cancer Journal for Clinicians, 65, 5-29. https://doi.org/10.3322/caac.21254

[3] Oluwole, O.P., Rafindadi, A.H., Shehu, M.S. and Samaila, M.O.A. (2015) A Ten-Year Study of prostate Cancer Specimens at Ahmadu Bello University Teaching Hospital Zaria. Nigeria African Journal of Urology, 21, 15-18. https://doi.org/10.1016/j.afju.2014.09.004

[4] American Cancer Society (2008) Cancer Facts \& Figures 2008. American Cancer Society, Atlanta.

[5] Amin, M., Boccon-Gibod, L., Egevad, L., Epstein, J.I., Humphrey, P.A., Mikuz, G., et al. (2005) Prognostic and Predictive Factors and Reporting of Prostate Carcinoma in Prostate Needle Biopsy Specimens. Scandinavian Journal of Urology and Nephrology, 216, 20-33. https://doi.org/10.1080/03008880510030923

[6] Ndoye, M., Niang, L., Gandaho, K.I., Jalloh, M., Labou, I. and Gueye, S. (2014) Cancer avancé de la prostate au Sénégal. Aspects diagnostiques à l'hôpital de Grand Yoff. Progrès en Urologie, 24, 271-275. https://doi.org/10.1016/j.purol.2013.08.317

[7] Osegbe, D.N. (1997) Prostate Cancer in Nigerians: Facts and Nonfacts. Journal of Urology, 157, 1340-1343. https://doi.org/10.1016/S0022-5347(01)64966-8

[8] Odedina, F.T., Akinremi, T.O., Chinegwundoh, F., Roberts, R., Yu, D., Reams, R.R. and Kumar, N. (2009) Prostate Cancer Disparities in Black Men of African Descent: A Comparative Literature Review of Prostate Cancer Burden among Black Men in the United States, Caribbean, United Kingdom, and West Africa. Infectious Agents and Cancer, 4, S2. https://doi.org/10.1186/1750-9378-4-S1-S2

[9] Gueye, S.M., Zeigler-Johnson, C.M., Friebel, T., Spangler, E., Jalloh, M., MacBride, S., et al. (2003) Clinical Characteristics of Prostate Cancer in African Americans, American Whites, and Senegalese Men. Urology, 61, 987-992. https://doi.org/10.1016/S0090-4295(02)02588-8

[10] Milton, S.B., Venceslau, R.S., Gladston, B.S., Alexandre, H. and Marco, A.S. (2003) Prevalence of Prostate Adenocarcinoma According to Race in a University Hospital. International Brazilian Journal of Urology, 29, 306-312. https://doi.org/10.1590/S1677-55382003000400004

[11] Akang, E.E., Aligbe, J.U. and Olisa, E.G. (1996) Prostatic Tumours in Benin City, Nigeria. West African Journal of Medicine, 15, 56-60.

[12] Echimane, A.K., Ahnoux, A.A., Adoubi, I., Hien, S., M’Bra, K., D’Horpock, A., et al. (2000) Cancer Incidence in Abidjan, Ivory Coast: First Results from Cancer Registry. Cancer, 89, 653-663. https://doi.org/10.1002/1097-0142(20000801)89:3<653::AID-CNCR22>3.0.CO;2-Z

[13] Angwafo, F.F. (1998) Migration and Prostate Cancer: An International Perspective. Journal of the National Medical Association, 90, S720-S723.

[14] Carter, H.B., Albertsen, P.C., Barry, M.J., Etzioni, R., Freedland, S.J., Greene, K.L., et al. (2013) Early Detection of Prostate Cancer: AUA Guideline. Journal of Urology, 190, 419-426. https://doi.org/10.1016/j.juro.2013.04.119 